\title{
EFFECT OF IMPLANTATION OF C, Si AND Cu INTO ZrNb NANOMETRIC MULTILAYERS
}

\author{
${ }^{1}$ Nabil DAGHBOUJ, ${ }^{1,2}$ Miroslav KARLÍK, ${ }^{3}$ Jan LÖRINČíK, ${ }^{4}$ Tomáš POLCAR, ${ }^{5}$ Mauro CALLISTI, \\ ${ }^{6}$ Vladimír HAVRÁNEK
}

\author{
${ }^{1}$ Department of Materials, Faculty of Nuclear Sciences and Physical Engineering, Czech Technical University \\ in Prague, Prague, Czech Republic, EU, Nabil.Daghbouj@fjfi.cvut.cz \\ ${ }^{2}$ Department of Physics of Materials, Faculty of Mathematics and Physics, Charles University, Prague, \\ Czech Republic, EU, Miroslav.Karlik@fifi.cvut.cz \\ ${ }^{3}$ Research Centre Řež, Husinec-Řež, Czech Republic, EU, jan.lorincik@cvrez.cz \\ ${ }^{4}$ Department of Control Engineering, Faculty of Electrical Engineering, Czech Technical University in Prague, \\ Prague, Czech Republic, EU, polcar@fel.cvut.cz \\ ${ }^{5}$ Department of Materials Science and Metallurgy, University of Cambridge, Cambridge, \\ United Kingdom, EU, M.Callisti@soton.ac.uk \\ ${ }^{6}$ Nuclear Physics Institute CAS, Řež, Czech Republic, EU, Havranek@ujf.cas.cz
}

https://doi.org/10.37904/metal.2019.735

\begin{abstract}
Sputter-deposited $\mathrm{Zr} / \mathrm{Nb}$ nanometric multilayer films with a periodicity $(\mathrm{L})$ in the range from 6 to $167 \mathrm{~nm}$ were subjected to carbon, silicon and copper ion irradiation with low and high fluences at room temperature. The ion profiles, mechanical proprieties, and disordering behavior have been investigated by using a variety of experimental techniques (Secondary lon Mass Spectrometry - SIMS, nanoindentation, X-ray diffraction - XRD, and scanning transmission electron microscopy - STEM). On the STEM bright field micrographs there is damage clearly visible on the surface side of the multilayer; deeper, the most damaged and disordered zone, located close to the maximum ion concentration, was observed. The in-depth $\mathrm{C}$ and $\mathrm{Si}$ concentration profiles obtained from SIMS were not affected by the periodicity of the nanolayers. This is in accordance with SRIM simulations. XRD and electron diffraction analyses suggest a structural evolution in relation to $L$. After irradiation, $\mathrm{Zr}(0002)$ and $\mathrm{Nb}(110)$ reflexions overlap for $\mathrm{L}=6 \mathrm{~nm}$. For the periodicity $\mathrm{L}>6 \mathrm{~nm}$ the $\mathrm{Zr}(0002)$ peak is shifted to higher angles and $\mathrm{Nb}(110)$ peak is shifted to lower angles.
\end{abstract}

Keywords: $\mathrm{Zr} / \mathrm{Nb}$ multilayers, ion irradiation, strain, XRD, SIMS

\section{INTRODUCTION}

Materials under extreme environments have received significant attention recently in the context of nextgeneration energy, defense, and transportation technologies. These applications require materials to perform at "extremes" of stress, temperature, irradiation dose, and corrosive environments [1]. The next-generation of nuclear power reactors require structural materials capable of withstanding elevated temperatures and radiation fluxes in highly corrosive environments for long periods of time without failure [1,2].

For that reason, a deeper understanding of materials behavior in extreme environments is essential to mitigate all radiation-induced defects improving the reliability, lifetime, and integrity of structural materials in advanced reactors. Materials containing a high concentration of interfaces promise to offer high resistance to radiation damage accumulation [3]. Enhanced radiation performance is due to grain boundaries and interfaces between incoherent nanoscale metallic multilayers (NMMs) that act as effective sinks for defect recombination at intersections between misfit dislocations [4]. 
The majority of previous studies focused on fcc/bcc multilayer systems such as $\mathrm{Cu} / \mathrm{Nb}$ [5], Ag/V [6], Cu/W [7], $\mathrm{Cu} / \mathrm{Fe}$ [8], and Ni/Fe [9] because the large lattice parameter mismatch of fcc/bcc interfaces enhances defect storage capability of multilayers [10]. Unfortunately, when high neutron-induced radioactivity is considered, only a few fcc metals could be used in nuclear reactors [10].

Recently, hcp-based NMMs started to attract some attention and cases of hcp-based NMMs are: Mg/Nb [11], $\mathrm{Zr} / \mathrm{Nb}$ [12,13], Co/Mo [14], Cu/Zr [15], etc. Most of the studies on hcp-based NMMs focused on the structure strength relationship of pristine NMMs, while no relevant investigations were performed to assess their behavior after ion irradiation. Only a few numbers of studies were conducted to assess the structural evolution of interfaces subjected to heavy ion irradiation [16]. Callisti et al. [16] investigated the structural stability and mechanical properties of sputter-deposited $\mathrm{Zr} / \mathrm{Nb}$ nanoscale multilayers subjected to Si-ion irradiation in relation to the individual layer thickness. It was shown that the interface density distribution played a major role in the nature and amount of accumulated radiation damage. Our study focuses on the strain evolution of $\mathrm{Zr} / \mathrm{Nb}$ NMMs with different periodicities $(\mathrm{L})$ due to different heavy ions $(\mathrm{C}, \mathrm{Si}, \mathrm{Cu})$ irradiation.

\section{MATERIALS AND METHODS}

Magnetron sputtering was employed to fabricate $\mathrm{Zr} / \mathrm{Nb}$ nanoscale metallic multilayers (NMMs). High-purity $\mathrm{Zr}$ and $\mathrm{Nb}$ targets were used to deposit NMMs with different periodicity (L) onto a single-crystal (111) Si substrate ( $L=6 \mathrm{~nm}$ (sample 03), $L=27 \mathrm{~nm}$ (sample 05), $L=60 \mathrm{~nm}$ (sample 06), $L=96 \mathrm{~nm}$ (sample 07)). Some samples of the as-deposited multilayers were irradiated by $\mathrm{Si}^{+}$ions with an energy of $1.8 \mathrm{MeV}$ and with two fluences (4.0x $10^{15} \mathrm{Si}^{+} / \mathrm{cm}^{2}(\mathrm{LF})$ and $\left.1.0 \times 10^{16} \mathrm{Si}^{+} / \mathrm{cm}^{2}(\mathrm{HF})\right)$, others were irradiated by $\mathrm{C}^{+}$ions with an energy of $1.4 \mathrm{MeV}$ and with low fluence $(\mathrm{LF})\left(1 \times 10^{16} \mathrm{C}^{+} / \mathrm{cm}^{2}\right)$ and to high fluence (HF) $\left(5 \times 10^{16} \mathrm{C}^{+} / \mathrm{cm}^{2}\right)$ and finally some samples were irradiated by $\mathrm{Cu}+$ with an energy of $2.25 \mathrm{MeV}$ and with low fluence $\left(1.5 \times 10^{15} \mathrm{Cu}^{+} / \mathrm{cm}^{2}\right)(\mathrm{LF})$ and high fluence $\left(4 \times 10^{15} \mathrm{Cu}^{+} / \mathrm{cm}^{2}\right)(\mathrm{HF})$. Here we report on the ion beam induced modifications of periodic $\mathrm{Zr} / \mathrm{Nb}$ multilayers (NMMs) and their analysis using combined X-ray diffraction, and secondary ion mass spectroscopy (SIMS) techniques. After ion irradiation, we have found dilatation of the $\mathrm{Nb}$ layers (positive out-of-plane strain for $L=6$, and $27 \mathrm{~nm}$ ) and compression of $\mathrm{Zr}$ layers. On the other hand, for $\mathrm{L}>27 \mathrm{~nm}$, a compressive strain in the multilayers was detected. SIMS profiles of ion irradiated materials have been obtained to understand the observed effects.

\section{RESULTS AND DISCUSSION}

\subsection{Ion distribution}

The as-implanted C, and Si concentration depth profiles measured by SIMS are in agreement with Stopping Range of lons in Matter code (SRIM) calculations (Figure 1). The agreement between experimental and simulated ion profiles also suggests that no long-range diffusion leading to the redistribution or escape of the implanted C, Si occurred. The second smaller peaks of $C$ ions close to substrate (Figures 1a, c) are most probably due to some contamination during sputtering deposition (they do not appear on Si irradiation profiles (Figures $1 b, d)$ ). All experimental SIMS ion profiles show oscillations in concentration following $\mathrm{Zr}$ and $\mathrm{Nb}$ layers. These oscillations are more pronounced in the samples 05 having higher periodicity $(\mathrm{L}=27 \mathrm{~nm}$ Figures 1c, d). From Figure 1e, where the $\mathrm{C}, \mathrm{Zr}$ and $\mathrm{Nb}$ SIMS profiles are plotted together, it can be noticed that the $\mathrm{Nb}$ layers trap more $\mathrm{C}^{+}$ions than the $\mathrm{Zr}$ ones. This is also observed for $\mathrm{Si}^{+}$ions, but the amplitude of the oscillations is not so pronounced (Figure 1d). These oscillations are also present in SRIM profiles (Figures 1a-d). The difference in the trapping power of $\mathrm{Nb}$ and $\mathrm{Zr}$ is most probably due to higher $\mathrm{Nb}$ density $\left(8.57 \mathrm{~g} / \mathrm{cm}^{3}\right)$ over $\mathrm{Zr}\left(6.52 \mathrm{~g} / \mathrm{cm}^{3}\right)$ and lower atomic packing factor $(68 \%)$ for bcc Nb lattice in comparison with $74 \%$ for hcp $\mathrm{Zr}$ lattice. It means that there is more free void space (32\%) in bcc unit cell than in hcp unit cell $(26 \%)$. Furthermore, the ratio between the trapped ion concentration is more significant at the maximum projected range $\left(R_{p} \sim 1200 \mathrm{~nm}\right)$ in Figures 1c, e. 


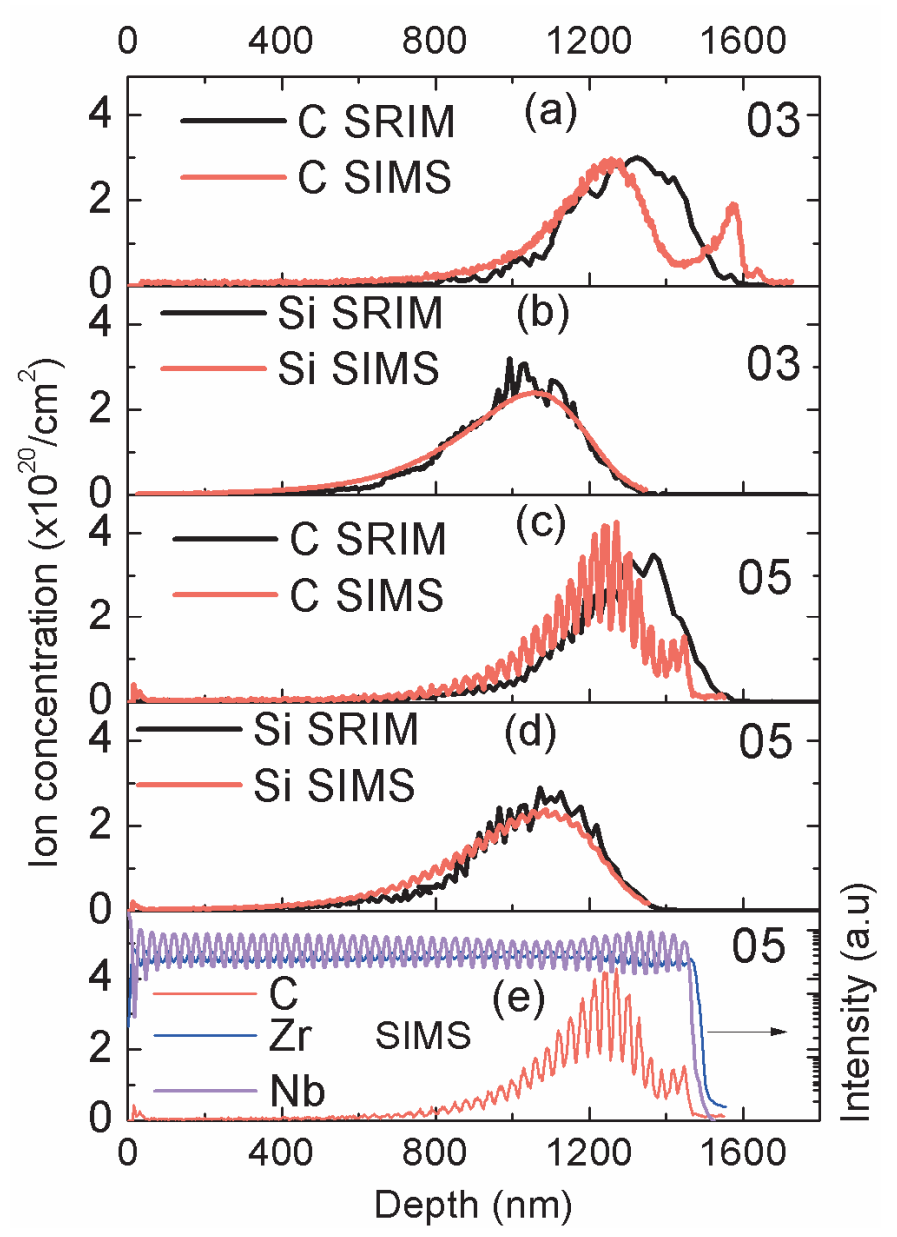

Figure 1 SIMS (red line) and SRIM (black line) profiles for $\mathrm{C}^{+}$and $\mathrm{Si}^{+}$ion irradiated samples: $(\mathrm{a}, \mathrm{b})$ - sample 03 (periodicity $6 \mathrm{~nm}$ ), (c,d) - sample 05 (periodicity $27 \mathrm{~nm}$ ), (e) SIMS profiles of C, Zr and Nb in the $\mathrm{C}^{+}$ irradiatied multilayer with periodicity $27 \mathrm{~nm}$ (sample 05).

\subsection{Microstructural evolution of irradiated $\mathrm{Zr} / \mathrm{Nb}$ multilayers}

Figure 2 shows the $X$-ray diffraction curves of four $\mathrm{Zr} / \mathrm{Nb}$ NMMs with different periodicities (L) before and after irradiation. The diffraction patterns for the as-deposited NMMs with $L>6 \mathrm{~nm}$ (samples $05,06,07$ ) appear with two peaks at Bragg angles $\theta_{B}=35.66^{\circ}$ and $\theta_{B}=38.37^{\circ}$, representing $\operatorname{Zr}(0002)$ and $\mathrm{Nb}(110)$ crystal planes, respectively [12]. In the case of the lowest periodicity ( $L=6 \mathrm{~nm}$, sample 03) the main Bragg peaks disappear and satellite peaks become even more prominent because of the increased degree of interfacial coherency between the layers. (for further details see Refs. $[12,16]$ ). After ion irradiation, all XRD peaks shift to higher angles except for $L=6 \mathrm{~nm}$, and $L=27 \mathrm{~nm}$, where the (110) Nb peak shifts to lower angles. This peak shift is characteristic of the lattice strain in the direction normal to the sample surface. Dilatation of the crystal lattice introduces shifts towards $\theta<\theta_{\mathrm{B}}$ (to the left). Conversely, compression of the crystal lattice introduces shifts towards $\theta>\theta_{B}$ (to the right).

Both the lattice parameters of the as-deposited $\mathrm{Zr}$ and $\mathrm{Nb}$ layers ( $d_{\text {as-dep layer }}$ ) and of the implanted layer ( $d_{\text {impl }}$ layer) follow Bragg's law, and so we can calculate strain from the difference of the as deposited Bragg angle $\left(\theta_{B}\right.$, as-dep) and the corresponding Bragg angle of irradiated samples with shift $\Delta \theta\left(\theta_{\mathrm{B} \text {, as dep }}+\Delta \theta\right)$. The out-of-plane (normal) strain $\varepsilon$ is expressed by equation:

$\varepsilon=\frac{d_{\text {impl layer }}-d_{\text {as }- \text { dep layer }}}{d_{\text {as }- \text { dep layer }}}=\frac{\sin (\theta \mathrm{B}, \text { as }- \text { dep })}{\sin (\theta \mathrm{B}, \text { as }-\operatorname{dep}+\Delta \theta)}-1$ 
The results of the calculations are summarized in Table 1. For $L=27 \mathrm{~nm}$ (sample 05) the shift of the peaks to the lower angle is corresponding to an out-of-plane lattice compression. The magnitude of out-of-plane strain is enhanced in multilayers with increasing of the ion fluence and reaches the largest value with $\mathrm{Cu}$ irradiation ( $3 \%$ - blue curve in Figure $\mathbf{2 b}$ - sample 05 , first $\mathrm{Nb}$ column in Table 1). On the other hand, $\mathrm{Zr}$ undergoes compression increasing with tensile strain in Nb layers. The highest value of $-1.3 \%$ out-of-plane lattice compression is reached with copper irradiation and high fluence (first $\mathrm{Zr}$ column in Table 1).

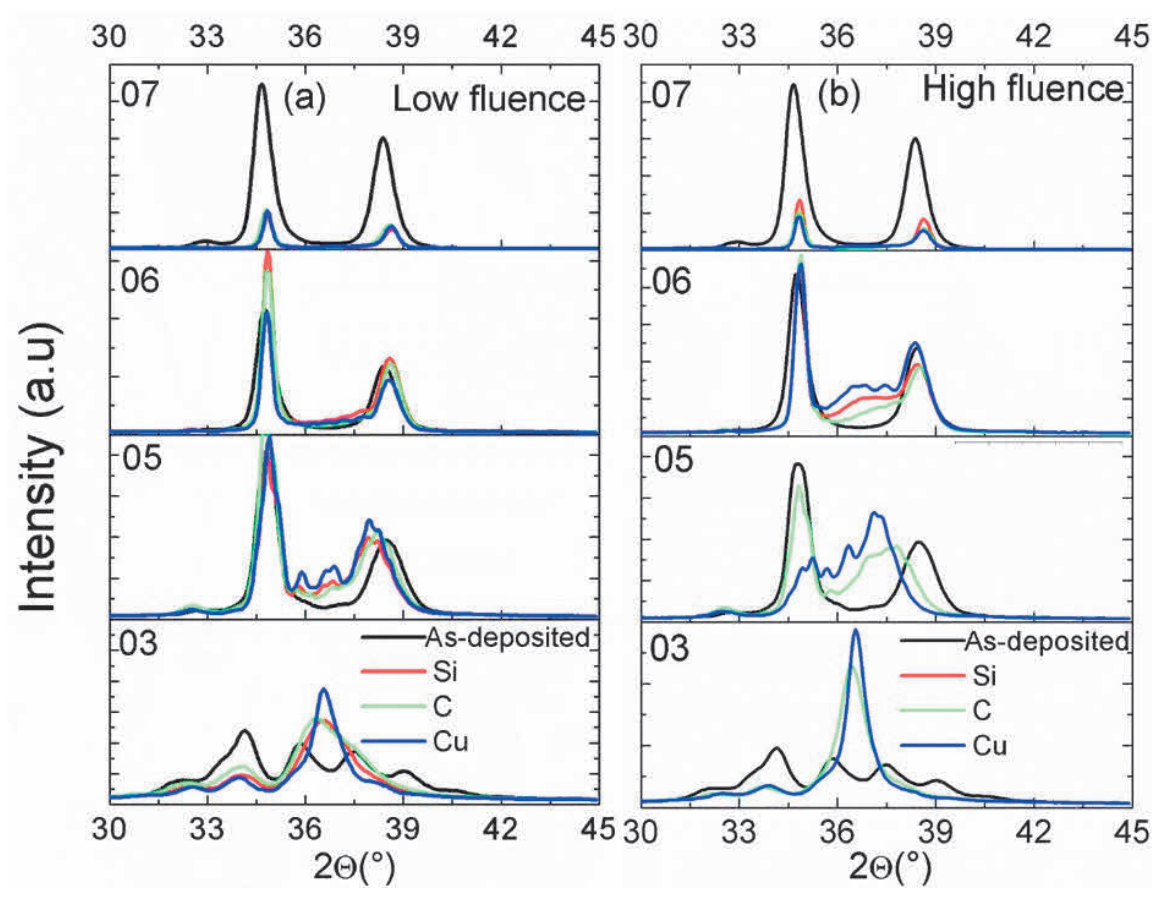

Figure $2 \mathrm{XRD}$ patterns for $\mathrm{Zr} / \mathrm{Nb}$ nanoscale metallic multilayers with different periodicities (sample 03 - $\mathrm{L}=6$ $\mathrm{nm}$, sample $05-\mathrm{L}=27 \mathrm{~nm}$, sample 06 - L=60 nm, sample 07 - L=96 nm) before and after $\mathrm{C}$, Si and $\mathrm{Cu}$ irradiation with (a) low fluence, (b) high fluence.

Table 1 Out-of-plane (normal) strain after irradiation

\begin{tabular}{|c|c|c|c|c|c|c|}
\hline \multirow{2}{*}{ Out-of-plane strain (\%) } & \multicolumn{2}{|c|}{$\mathbf{0 5}$} & \multicolumn{2}{c|}{$\mathbf{0 6}$} & \multicolumn{2}{c|}{$\mathbf{0 7}$} \\
\cline { 2 - 7 } & $\mathbf{N b}$ & $\mathbf{Z r}$ & $\mathbf{N b}$ & $\mathbf{Z r}$ & $\mathbf{N b}$ & $\mathbf{Z r}$ \\
\hline $\mathrm{C}(\mathrm{LF})$ & +0.8 & -0.02 & -0.4 & -0.2 & -0.4 & -0.4 \\
\hline $\mathrm{Si}(\mathrm{LF})$ & +0.8 & -0.07 & -0.4 & -0.2 & -0.58 & -0.4 \\
\hline $\mathrm{Cu}(\mathrm{LF})$ & +1.3 & -0.2 & -0.3 & -0.2 & -0.58 & -0.3 \\
\hline $\mathrm{C}(\mathrm{HF})$ & +2.1 & -0.1 & -0.2 & -0.4 & -0.6 & -0.7 \\
\hline $\mathrm{Si}(\mathrm{HF})$ & - & - & 0 & -0.4 & -0.6 & -0.7 \\
\hline $\mathrm{Cu}(\mathrm{HF})$ & +3 & -1.3 & 0.2 & -0.4 & -0.6 & -0.7 \\
\hline
\end{tabular}

In the case of $\mathrm{Zr} / \mathrm{Nb}$ multilayers with the lowest periodicity ( $\mathrm{L}=6 \mathrm{~nm}$ - sample 03 ) the $\mathrm{Zr}$ and $\mathrm{Nb}$ peaks overlap with each other due to the superlattice effect in diffraction. The diffraction patterns are thus more complex. The corresponding strains were not calculated, but they can be qualitatively estimated. Only one important peak is visible after irradiation (located at $36.53^{\circ}$ ), which is sharper for $\mathrm{Cu}^{+}$ion irradiation with high fluence (Figure $\mathbf{2 b}$, sample 03). In comparison with the sample $05(L=27 \mathrm{~nm})$ the shift of the peaks follows the same trend (Nb shifts to the left, and $\mathrm{Zr}$ to the right). This means that $\mathrm{Nb}$ layers are in tension, while $\mathrm{Zr}$ layers are in compression. As the shift of the peaks is more significant for the sample 03, the strain should be more important 
than in the 05 sample $(L=27)$, i.e. higher than $+3 \%$ out-of-plane lattice expansion in $\mathrm{Nb}$ and more negative than $-1.3 \%$ lattice compression in $\mathrm{Zr}$ layers.

For L> $27 \mathrm{~nm}$, after all ion implantations, all XRD peaks shift to higher angles, corresponding to an out-of-plane lattice compression. The magnitude of the out-of-plane strain is enhanced in multilayers with increasing layer thickness and reaches the largest value for $\mathrm{Cu}^{+}$irradiation with high fluence. In general, factors such as isolated $\mathrm{C}$, Si and $\mathrm{Cu}$ atoms, self-interstitials, vacancies, interstitial loops, vacancy clusters and the geometric constraint of the metal layers from the rigid Si substrate are the major contributions to lattice distortions. During room temperature implantation, isolated interstitials prefer to migrate to interfaces (particularly when the interface spacing is a few nanometers $L=6 \mathrm{~nm}$, and $27 \mathrm{~nm}$ ) or to form interstitial loops (for thicker layers, $L>27 \mathrm{~nm}$ ). Hence the overall concentration of interstitials induces a compressive or tensile stress. This strain is more pronounced in $\mathrm{Nb}$ layers. This can be explained by higher ion concentration trapped in Nb layers (Figure 1).

\section{CONCLUSIONS}

We examined the effects of radiation damage on the structural properties of $\mathrm{Zr} / \mathrm{Nb}$ nanoscale metallic multilayers with different periodicities. For the multilayer with a periodicity of $6 \mathrm{~nm}$, and $27 \mathrm{~nm}, \mathrm{Si}, \mathrm{C}$ and $\mathrm{Cu}-$ ion irradiation led to a tensile strain of $\mathrm{Nb}$ layers and compressive strain of $\mathrm{Zr}$ layers. This strain evolution is more significant for $\mathrm{Cu}$ irradiation with high fluence. On the other hand, for $\mathrm{L}>27 \mathrm{~nm}$, both $\mathrm{Zr}$ and $\mathrm{Nb}$ layers exhibit compressive out-of-plane strain. The strain (tensile or compressive) is more pronounced in Nb layers due to higher trapping power of $\mathrm{Nb}$ with respect to $\mathrm{Zr}$, which was measured by secondary ion mass spectrometry.

\section{ACKNOWLEDGEMENTS}

Financial support of the European Regional Development Fund (project No. CZ.02.1.01/0.0/0.0/15_003/0000485) and of the Czech Science Foundation (project 17-17921S) is gratefully acknowledged. The irradiation experiments were carried out at the Centre of Accelerators and Nuclear Analytical Methods (CANAM) infrastructure LM 2015056, supported by OP RDE, MEYS, Czech Republic under the project CANAM OP, CZ.02.1.01/0.0/0.0/16_013/0001812.

\section{REFERENCES}

[1] ZINKLE, S.J., BUSBY, J.T., Structural materials for fission \& fusion energy, Mater. Today 12 (2009) 12-19.

[2] ZINKLE, S.J., WAS, G.S., Materials challenges in nuclear energy, Acta Mater. 61 (2013) 735-758.

[3] DEMKOWICZ, M. J., HOAGLAND, R. G., and HIRTH, J. P., Interface structure and radiation damage resistance in Cu-Nb multilayer nanocomposites, Phys. Rev. Lett. 100, 136102 (2008).

[4] DEMKOWICZ, M. J., MISRA, A. and CARO, A., The role of interface structure in controlling high helium concentrations, Curr. Opin. Solid State Mater. Sci. 16, 101 (2012).

[5] DEMKOWICZ, M.J., WANG, Y.Q., HOAGLAND, R.G. ANDEROGLU, O., Mechanisms of He escape during implantation in CuNb multilayer composites, Nucl. Instrum. Methods Phys. Res. B: Beam Interact. Mater. At. 261 (2007) 524-528.

[6] WEI, Q.M., LI. N., MARA, N., NASTASI, M., MISRA, A., Suppression of irradiation hardening in nanoscale VIAg multilayers, Acta Mater. 59 (2011) 6331-6340.

[7] GAO, Y., YANG, T.F., XUE, J.M., YAN, S., ZHOU, S.Q., WANG, Y.G. KWOK, D.T.K., CHU, P.K., ZHANG, Y.W., Radiation tolerance of Cu/W multilayered nanocomposites, J. Nucl. Mater. 1 (2011) 11-15.

[8] WEI, K.F., WANG, Z.G., LIU, C.B., ZANG, H., YAO, C.F., SHENG, Y.B., MA, Y.Z., SONG, Y., LU, Z.W., Modification of Fe/Cu multilayers under $400 \mathrm{keV}$ Xe20+ irradiation, Chin. Phys. C 32 (2008) 262-264.

[9] CHEN, F.D., TANG, X.B., YANG, Y.H., HUANG, H., CHEN, D., Investigation of structural stability and magnetic properties of Fe/Ni multilayers irradiated by 300 keV Fe10+, J. Nucl. Mater. 452 (2014) 31-36. 
[10] DEMKOWICZ, M.J., HOAGLAND, R.G., HIRTH, J.P., Interface structure and radiation damage resistance in Cu$\mathrm{Nb}$ multilayer nanocomposites, Phys. Rev. Lett. 100 (2008) 136102.

[11] HAM, B. and ZHANG, X. High strength Mg/Nb nanolayer composites, Mater. Sci. Eng. A 528 (2011) 2028-2033.

[12] CALLISTI, M. POLCAR, T., Combined size and texture-dependent deformation and strengthening mechanisms in $\mathrm{Zr} / \mathrm{Nb}$ nano-multilayers, Acta Mater. 124 (2017) 247-260.

[13] MONCLÚS, M.A., CALLISTI, M., POLCAR, T., YANG, L.W., LLORCA, J., MOLINA-ALDAREGUÍA, J.M., Selective oxidation-induced strengthening of $\mathrm{Zr} / \mathrm{Nb}$ nanoscale multilayers, Acta Mater. 122 (2017) 1-10.

[14] YANG, G.H., ZHAO, B., GAO, Y., PAN, F., Investigation of nanoindentation on Co/Mo multilayers by the continuous stiffness measurement technique, Surf. Coat. Technol. 191 (2005) 127-133.

[15] ZHANG, J.Y., LEI, S., LIU, Y., NIU, J.J., CHEN, Y., LIU, G., ZHANG, X., SUN, J., Length scale-dependent deformation behavior of nanolayered Cu/Zr micropillars, Acta Mater. 60 (2012) 1610-1622.

[16] CALLISTI, M., KARLIK, M., POLCAR, T., Competing mechanisms on the strength of ion-irradiated $\mathrm{Zr} / \mathrm{Nb}$ nanoscale multilayers: Interface strength versus radiation hardening, Scripta Mater. 152 (2018) 31-35 